\title{
EDITORIAL
}

\section{Chronic kidney disease of unknown etiology: Mystery unsolved}

New form of chronic kidney disease (CKD) that cannot be attributed to diabetes, hypertension, primary glomerular nephrities or other known etiologies has encountered in the predominantly agricultural areas in the Northern Central Province of Sri Lanka. It has reached epidemic proportions with ever increasing numbers of patients and deaths, thus becoming a new and emerging health issue (Athuraliya et al., 2003, 2006; Chandrajith, et al., 2009, 2011; Jayasumana et al., 2011) that would eventually inflict adverse consequences on national food security, merely for the fact that affected populations constitute major rice farming communities in Sri Lanka. This disease exclusively occurs in settlements where groundwater is the main source of drinking water and it is more common among members of lower socio-economic strata, particularly the farmers. Due to its unique geographical distribution and histopathological evidence, causality has been speculated to be an environmentally induced problem (Chandrajith et al., 2011; Wanigasuriya et al., 2007), that is observed not only in Sri Lanka but also in most other developing countries where agriculture is the primary means of income (Nahas and Belle, 2005).

Etiology of this disease has since been attributed to a range of causes, including presence of the heavy metal cadmium in water that would potentially have introduced to water from inorganic fertilizer used in paddy fields (Bandara et al., 2010, 2008), presence of excessive amounts of fluoride in drinking water and prevalent use of low quality aluminum utensils (Herath et al., 2005), presence of toxins produced by microorganisms such as cyanobacteria in water and presence of radionuclides introduced by inorganic fertilizer (Chandrajith et al., 2011). Despite the said research efforts over the last decade, none of these hypotheses have been supported with adequate evidence. Therefore, causative factors and etiology of this chronic kidney disease is still considered uncertain or unknown and abbreviated as CKDu. As there is no cure available in the system of western medicine for $\mathrm{CKDu}$, prevention is of utmost importance. Prevention or/and cure in turn, is impossible a task without adequate knowledge on causality of the disease and mechanisms leading to renal failure (Abeysekera, 1996). Chandrajith et al., (2011) reported that higher fluoride levels are common in drinking water not only in disease prevalent areas but also in other areas unaffected by the disease, nevertheless they have observed greater incidence of the disease in areas where calcium carbonate hardness in groundwater is high. Chandrajith et al., (2010) have also shown that nephrotoxic metals such as $\mathrm{Cd}, \mathrm{U}$ and $\mathrm{Al}$ could be eliminated as causative agents on account of their very low presence in water. Hypothesis that microcystis, the toxin produced by certain species of freshwater cyanobacteria present in reservoir waters, is the causative agent of CKDu was not supported as no evidence was available for their abundant presence in well water, the source of drinking water for majority of CKDu patients. On the contrary, inhabitants in disease endemic areas who use reservoir water for drinking were not affected with the disease. Evidence is emerging that the potential causative agent of CKDu in Mahawilachchiya and Padaviya areas may be the presence of arsenic (As) in groundwater $(100-200 \mu \mathrm{g} / \mathrm{L})$ as arsenic poisoning symptoms, i.e. hyper-pigmentation and keratosis in palms and soles, presence of high As content in hair $(3-10 \mathrm{mg} / \mathrm{kg}$ ) and body parts of deceased CKDu patients have been reported (Jayasumana, 2011; Jayasumana et al., 2012).

These preliminary investigations have also revealed high mercury $(\mathrm{Hg})$ levels in groundwater (10-30 $\mu \mathrm{g} / \mathrm{L})$. As- content in rice produced in the endemic areas have been detected to be as high as 100-500 $\mu \mathrm{g} / \mathrm{kg}$ (Chandrajith et al., 2010; Jayasumana, 2011) and this could be another potential means through which As enters human body, as reported in Bangladesh where the highest number of Aspoisoning cases due to consumption of As-polluted groundwater and rice has been found (Naha \& Belle, 2005). It has also been observed that the number of CKDu patients recorded had a marked positive relationship with the extent of ground water hardness and soil type that presumed to have high heavy metal retention capacity due to their unique chemical property, high cation exchange capacity (Amarasinghe, 2004; Jayasumana, 2011; Fonseka et al., 2012). 
Above observations suggest the potential causative factors for the unique distribution of $\mathrm{CKDu}$, i.e. effect of groundwater hardness, presence of arsenic in water and type of soil on human health and also their socio-economic status need further investigations to produce data from other parts of $\mathrm{CKDu}$ endemic areas. No studies are reported on effect of climate and its envisaged change on catchment hydrology, groundwater quality and movement as well as factors affecting pollutant distribution within water tables. Besides, some studies have shown that the presence of arsenic in pesticides and fertilizer imported to Sri Lanka (Paranagama et al., 2012; Jayasumana et al., 2012) despite importation of $\mathrm{As}$ and $\mathrm{Hg}$ containing pesticides is illegal according to the Pesticides Control Act of 1981. Fertilizers contain considerable amounts of As and other heavy metals as impurities. The most recent evidence on the etiology of CKDu is contained in the interim reports and final report of the investigations carried out in Padaviya area in Anuradhapura District by the WHO (2013) and it states that nephrotoxic agrochemicals, arsenic and cadmium are the most potential causative agents of $\mathrm{CKDu}$ as they have found above normal levels of arsenic and cadmium levels in hair, nails and urine of the $\mathrm{CKDu}$ patients. Recent studies show that cadmium exposure through rice in Sri Lanka is remarkably high compared to the other Asian rice producing nations (Meherg et al., 2013). New hypothesis of Glyphosate and nephrotoxic metals forming complexes with hard water is emerging (Jayasumana et al., 2014) and backed by the WHO report where residues of glyphosates and its degradation products were recorded in urine samples.

$\mathrm{CKDu}$ is slowly progressive and starting second decade of life in other parts of the country. It should be noted that it was asymptomatic until it reach epidemic states in the North Central Province in Sri Lanka. It has already become a major public health problem resulting immense social economic and health impacts. Recent reports indicate that CKDu is emerging within farming communities in Southern and adjacent lower part of the Uva province. Increasing number of patients has been reported in Wellawaya, Thelulla and Thanamalwila in Uva provinve and Thissamaharamaya and Lunugamwehera in Southern province. Biogeography and environmental variables of Southern and Uva provinces may significantly differ from the North Central province, nevertheless potential causative agents such as nephrotoxic agrochemicals, arsenic and cadmium and their effects may be similar. However, it is clear that affected farming communities have no direct access to the clean water. Water may be an important carrier of the causative agent and therefore, clean water supply in the disease prevalent areas should be given the priority. In addition, short, medium and long term strategies proposed by the WHO report in 2013 should be given due recognition and implementation of recommendations should commence without further delay. It is speculated that the mystery of the disease and its etiology will remain unsolved for decades, but precautions and strategies to prevent $\mathrm{CKDu}$ is prerequisite.

\section{References}

1. Abeysekera D.T.D.J., Kaiyoom S.A.A. and Dissanayake S.U. (1996). Place of peritoneal dialysis in the management of renal failure patients admitted to General Hospital Kandy. Kandy Society of Medicine 18th Annual Academic Conference.

2. Amarasinghe M.D., Liyanage J.and Nirbadha K.G.S. (2004). Presence of heavy metals in plants of a tropical wetland in Sri Lanka, as an indicator of their phytoremediation potential. Proc. World Conference on Environmental Management. Universiti Kebangsaan Malaysia.

3. Athuraliya T.N.C., Abeysekera D.T.D.J., Amerasinghe P.H., Kumarasiri P.V.R. and Dissanayake V. (2009). Prevalence of chronic kidney disease in two tertiary care hospitals: high proportion of cases with uncertain etiology. Ceylon Medical Journal, 54(1): 23-25.

4. Athuraliya T.N.C, Abeysekera.T, AmerasingheP.H., Kumarasiri R., Abeysekera C., Gooneratna A. and Bandara P. (2003). A Baseline study on early renal disease in a selected community of the North Central Province of Sri Lanka. Faculty of Medicine \& Science, University of Peradeniya, Research Report.

5. Bandara J.M., Senevirathna D.M., Dasanayake D.M., Herath V., Bandara J.M., Abeysekara T. and Rajapaksha K.H. (2008). Chronic renal failure among farmer families in cascade irrigation systems in Sri Lanka associated with elevated dietary cadmium levels in rice and freshwater fish (Tilapia). Environ Geochem Health 30(5):465-78. 
6. Chandrajith R., Dissanayake C.B., Ariyarathna T., Herath H.M.J.M.K. and Padmasiri J.P. (2011). Dose-dependent $\mathrm{Na}$ and $\mathrm{Ca}$ in fluoriderich drinking water - Another major cause of chronic renal failure in tropical arid regions. Science of the Total Environment 409: 671-675.

7. Chandrajith R., Senevirathne S., Wickremarachchi K., Attanayake T., Athuraliya T. N. C and Dissanayake C. B. (2009). Natural radionuclides and trace elements in rice field soils in relation to fertilizer application: Study of a chronic kidney disease area in Sri Lanka. Environ. Earth. Sci. 60:193-201.

8. Jayasumana, C. S. (2011). Potential relationship between chronic kidney disease of unknown etiology and presence of arsenic in ground water in North Central, Uva and Eastern Provinces. A paper presented at the National Workshop on "Challenges in Groundwater Resources Management in Sri Lanka" organized by the Water Resources Board of Sri Lanka, Colombo, March 2011.

9. Jayasumana C., Gunatilake S. and Senanayake P. (2014). Glyphosate, hard water and nephrotoxic metals: Are they the culprits behind the epidemic of chronic kidney disease of unknown etiology in Sri Lanka? Int. J. Environ. Res. Public Health 2125-2147.
10. Meharg, A.A., Norton G., Deacon C., Williams P., Adomako E. E., Price A., Zhu Y., Li G., Zhao F., McGrath S., Villada A., Sommella A., Magala P., De Silva C. S., Brammer H., Dasgupta T., and Islam M.R. (2013). Variation in rice cadmium related to human Exposure. Environ. Sci. Technol. 47: 5613-5618.

11. Naha A.M.E.I. and Belle A.K. (2005). Chronic kidney disease: the global challenge. The Lancet, 365: 331-340.

12. Paranagama P.A., Jayasumana M.A.C.S., Amarasinghe M. and Fonseka S.I. (2012). Presence of Arsenic in pesticides used in Sri Lanka. Proceedings of the International Symposium on Water Quality and Health, Postgraduate Institute of Agriculture, Peradeniya.

13. Wanigasuriya K.P, Peiris-John R.J., Wickremasinghe R. and Hittarage A. (2007). Chronic renal failure in north central province of Sri Lanka: an environmentally induced disease. Transactions of the Royal Society of Tropical Medicine and Hygiene 101(10):1013-1017.

14. WHO (2013). Investigation and evaluation of chronic kidney disease of uncertain etiology in Sri Lanka. Final report, World Health Organization, Geneva, Switzerland.

P. Mangala C. S. De Silva

Department of Zoology

Faculty of Science, University of Ruhuna,

Matara, Sri Lanka.

Correspondence: chathura@zoo.ruh.ac.lk 